\title{
At-home Plant Growing Kits Foster Positive Student Experiences in an Online Horticulture Course
}

\author{
Gerardo H. Nunez ${ }^{1}$ and Mariana Neves da Silva ${ }^{1}$
}

AdDitional INDEX wORDs. distance education, experiential learning, online teaching, text mining

SUMmARY. Hands-on activities are an essential part of horticulture education. However, facilitating hands-on activities in online horticulture courses is challenging partly due to a lack of literature that describes remote laboratories in the discipline. Here we describe our experience planning and executing a remote strawberrygrowing activity in an online horticulture course at the University of Florida, Gainesville. Students received strawberry-growing kits that contained a strawberry (Fragaria $\times$ ananassa) plant, substrate, and fertilizer. Instructions on growing the strawberry plant were delivered online and students had to provide weekly updates about the status of their plant for 5 weeks. At the end of the semester, students provided feedback about the hands-on activity in the form of an essay. Their answers were analyzed using text mining to gauge their perception of the activity. About $77 \%$ of students expressed positive sentiments about the remote activity including excitement, enjoyment, and knowledge gain. Students who expressed negative sentiments about the activity $(\approx 23 \%$ of the total) focused on plant casualties and difficulties related to management practices. Overall, student essays and weekly updates reflected a relevant and engaging cognitive exercise in horticulture. Our results suggest that remote laboratories can improve the student experience in online courses and provide a footprint for successful implementation of similar activities in online horticulture courses.

$\mathrm{U}$ niversities have been offering online classes since the $1990 \mathrm{~s}$ (Volery and Lord, 2000). The ability to meet diverse educational needs and reach distant locations has supported steady growth in enrollment in these courses (De Brey et al., 2021). For example, about onethird of all undergraduate students were taking online courses before 2020 (Zimmerman, 2020). However, adoption of online education has not been even among disciplines. Online courses and academic programs in horticulture are still relatively rare. One of the reasons for this lag in adoption is that hands-on activities, laboratories, and field trips (collectively called experiential learning) are commonplace in horticulture education but their

Received for publication 22 Apr. 2021. Accepted for publication 16 Aug. 2021.

Published online 30 September 2021

${ }^{1}$ Horticultural Sciences Department, University of Florida, Gainesville, FL 32611

G.H.N. is the corresponding author. E-mail: g.nunez@ufl.edu.

This is an open access article distributed under the CC BY-NC-ND license (https://creativecommons. org/licenses/by-nc-nd/4.0/).

https://doi.org/10.21273/HORTTECH04882-21 implementation in online courses is challenging. Experiential learning enhances the student experience (Lindsey, 2019; Nunez, 2020), promotes learning, and fosters skill development (Craver and Williams, 2014; Fry et al., 2021; St. Hilaire et al., 2009; Uchanski et al., 2015). Thus, the quality of horticulture courses might suffer if online education precludes or diminishes experiential learning.

While instructors in other disciplines can use predesigned activities available from commercial vendors (Alvarez, 2021), horticulture instructors must plan and administer their own remote hands-on activities. Unfortunately, there is a lack of literature to support this process. Examples of successful hands-on activities for online horticulture courses are absent from the literature. Also absent are studies that report the academic and personal impact of hands-on activities in online horticulture courses. Thus, scholarly literature that highlights successfully executed, online hands-on activities can support the adoption of experiential learning in online horticulture courses.

Here we report our experience planning and administering a remote hands-on activity using strawberry (Fragaria $\times$ ananassa) growing kits as a part of an online horticulture course. We also investigated student perception of this hands-on activity using a text mining approach.

\section{Materials and methods}

This Institutional Review Boardapproved study (IRB 2020-01834) was conducted in FRC 1010-Growing Fruit for Fun and Profit, during the Spring 2020 and Summer 2020 semesters. FRC 1010 is a fully online, general interest undergraduate course at the University of Florida, Gainesville. This one-credit course focuses on fruit crop biology and cultivation. There were 144 students in FRC 1010 during the Spring 2020 semester and 69 students during the Summer 2020 semester. About $80 \%$ and $63 \%$ of the students were pursuing majors outside of the College of Agricultural and Life Sciences during spring and summer semesters, respectively. These enrollment figures are considered typical for this course (Nunez et al., 2014, 2016).

A remote strawberry-growing exercise was designed to increase student engagement and reinforce topics covered during lecture. We prepared strawberry-growing kits that contained a plastic pot (4-inch diameter), $40 \mathrm{~mL}(\approx 4.05 \mathrm{~g})$ of perlite, $0.47 \mathrm{~L}$ $(\approx 110 \mathrm{~g})$ of coconut coir, $10 \mathrm{~g}$ of $18 \mathrm{~N}-2.62 \mathrm{P}-5.81 \mathrm{~K}$ controlled-release fertilizer (Florikan, Sarasota, FL), and one strawberry plant. Bare-root strawberry runners were purchased from a commercial nursery (Bob Wells Nursery, Mineola, TX) and rooted in 72 -cell trays $(1.5 \times 1.5 \times 2.25$ inches $)$ filled with a commercial propagation

\begin{tabular}{llll}
\hline $\begin{array}{l}\text { Units } \\
\begin{array}{l}\text { To convert U.S. to SI, } \\
\text { multiply by }\end{array}\end{array}$ & U.S. unit & SI unit & $\begin{array}{l}\text { To convert SI to U.S., } \\
\text { multiply by }\end{array}$ \\
\hline 0.2366 & $\mathrm{cup}(\mathrm{s})$ & $\mathrm{L}$ & 4.2268 \\
29.5735 & $\mathrm{fl} \mathrm{oz}$ & $\mathrm{mL}$ & 0.0338 \\
3.7854 & $\mathrm{gal}$ & $\mathrm{L}$ & 0.2642 \\
2.54 & inch $(\mathrm{es})$ & $\mathrm{cm}$ & 0.3937 \\
28.3495 & $\mathrm{oz}$ & $\mathrm{g}$ & 0.0353
\end{tabular}


mix. Cultivar Strawberry Festival was used in the spring semester and cultivar Camarosa was used in the summer semester. Most plants had one to two leaves at the time of packing. Strawberry-growing kits were picked up by students from the University of Florida main campus in Gainesville, or packed in media mail bags and shipped as priority mail through the U.S. Postal Service. Shipped strawberry kits arrived at their destination within $48 \mathrm{~h}$ of shipping. Preparing and shipping the strawberry growing kits took $\approx 40 \mathrm{~h}$ in the spring semester and $\approx 20 \mathrm{~h}$ in the summer semester.

The hands-on activity lasted 5 weeks. Students were instructed to transplant their strawberry plant as soon as they received it (week 1 ). Then, students were instructed to optimize their watering practices (week 2 ), scout for insect pests (week 3 ), diagnose abiotic stress (week 4), and identify reproductive organs (week 5). Step-by-step instructions were delivered through video demonstrations, written directions, and infographics (Supplemental Fig. 1). Students provided weekly updates about their strawberry plant through the course learning management system. Student updates were graded, and they collectively accounted for $10 \%$ of the course grade.

At the end of the course, students were invited to provide anonymous feedback about the activity in the form of a 200-word essay. These questions were used to elicit student responses: What did you learn in the activity? What was exciting about the activity? What was disappointing or discouraging about the activity? Was growing strawberries easier or more difficult than you imagined? If you could start over, what would you do differently with your strawberry plant? Students who provided their feedback received two extra credit points (equivalent to $2 \%$ of the final grade).

During the Spring 2020 semester, 131 students provided feedback essays about the activity. During the Summer 2020 semester, 45 provided feedback essays. Student feedback essays were deidentified and analyzed using the text mining approach described in Nunez (2020). Briefly, text data were imported into statistical analysis software $(\mathrm{R}$ version 3.6.2; $\mathrm{R}$ Foundation for Statistical Computing, Vienna, Austria). This step removes apostrophes and capitalization from the text. Then, text data were separated into unigrams (one-word objects) or trigrams (threeword objects). Following, noninformative words (e.g., "to," "and," "the," etc.) were removed from the data set. Then, the overall sentiment in each essay was calculated using the inner join command in package dplyr (Wickham et al., 2018) and lexica included in package tidytext (Silge and Robinson, 2016). Three different lexica were used to produce sentiment scores from each essay: Afinn (Nielsen, 2011), Bing (Hu and Liu, 2004), and NRC (Mohammad and Turney, 2013). Sentiment scores produced with each lexicon were compared between the spring and summer semesters using Kruskal-Wallis nonparametric analysis of variance at $\alpha=0.05$.

Sentiment scores extracted with the Bing lexicon were used to separate students into two groups: students who expressed positive sentiments about the strawberry growing activity (scores $\geq 0$ ) and students who expressed negative sentiments about the activity (scores $<0$ ). Bing scores were used for grouping because this lexicon was developed to analyze customer product reviews and distinguish positive from negative features in the text (Hu and Liu, 2004). The most important trigrams in positive and negative essays were identified using the term frequency-inverse document frequency (tf-idf) index as per Silge and Robinson (2016). Code used for this analysis is publicly available (Nunez, 2019). Data were illustrated using $R$ package ggplot2 (Wickham, 2016).

\section{Results and discussion}

The time and resources dedicated to preparing for this activity were in line with time and resources necessary to facilitate a multiweek hands-on laboratory for a face-to-face course. At the start of the activity, plants picked up from campus were generally in better condition than plants shipped to students. A small fraction of the shipped plants $(\approx 7 \%)$ arrived at their destination dead. Whenever this happened, replacement plants were mailed to students. Instructors planning similar activities would benefit from having extra plants ready to be shipped as necessary. Alternatively, strawberry plants could be replaced by seeds, dormant plants, or other species that can tolerate shipping conditions better.
On average, sentiments were not different between the spring and summer semesters $(P>0.13$ in all cases $)$, suggesting that scaling up the activity to enrollments over 100 students was possible without affecting the student experience. About $77 \%$ of students expressed positive sentiments about growing a strawberry plant at home (Fig. 1A): 104 students in the spring semester and 31 students in the summer semester. Essays where students expressed positive sentiments mentioned excitement, enjoyment, and knowledge gain (Fig. 1B). Weekly updates from several students focused on happiness derived from observing healthy plants and anticipation for bloom and harvest. Positive responses are consistent with previous reports where hands-on activities fostered positive student experiences in agriculture courses (Lindsey, 2019; Nunez, 2020). These results also support previous findings where the combination of online and offline activities (also known as blended learning) was well received by horticulture students (Zhou and Chen, 2021).

About 23\% of students expressed overall negative sentiments about the activity: 27 students during the spring semester and 14 students during the summer semester. Essays written by students who expressed negative sentiments referred to the challenges of growing strawberry plants indoors, biotic and abiotic stress, and plant casualties (Fig. 1B). These themes were also present in student weekly updates. Overwatering was the most common problem observed in weekly updates. Students whose plants died during the activity expressed concern about the impact this would have on their grade. In future offerings, greater emphasis should be placed on irrigation instructions and/or a substrate with lower water-holding capacity should be included in the strawberrygrowing kit. Additionally, considering most students did not have optimum spaces to grow plants, the strawberrygrowing activity could carry fewer points or be entirely not graded.

The academic benefits derived from the remote strawberry-growing activity might extend beyond student perception. Growing a live plant as a part of a course assignment provided students with a real-life scenario where information retrieval, critical thinking, 

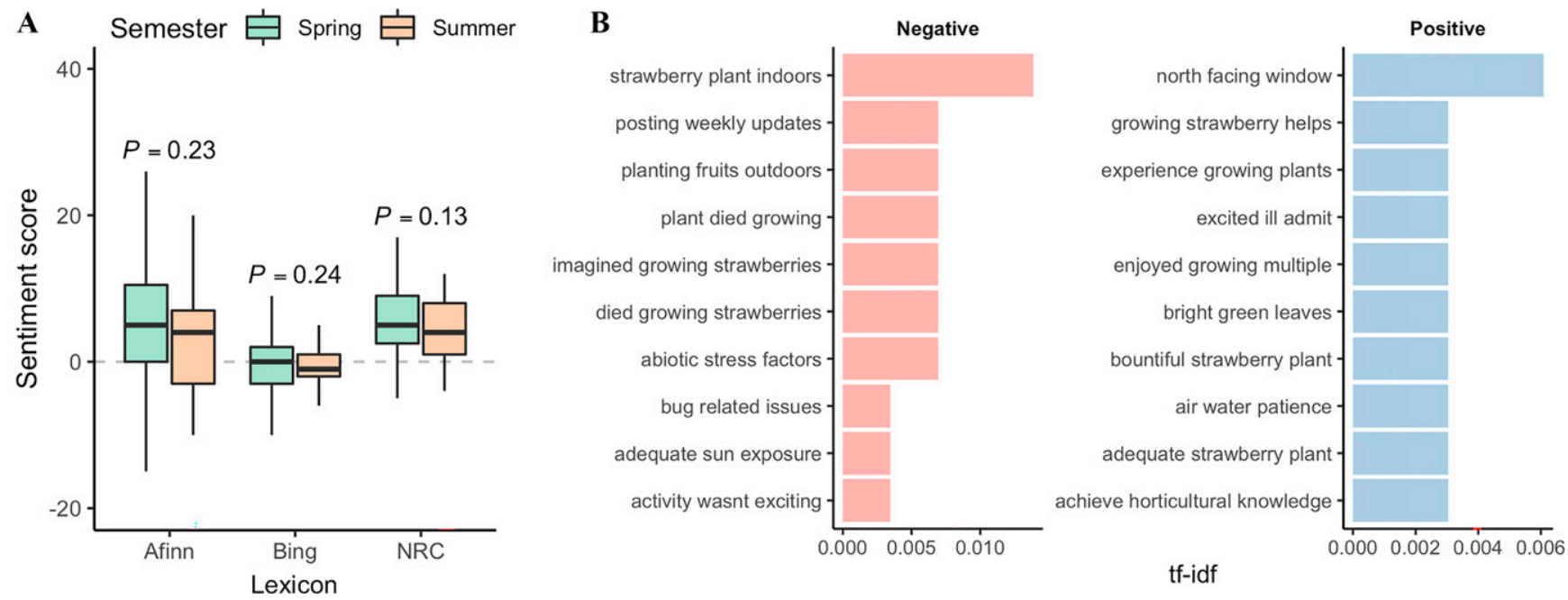

Fig. 1. (A) Overall sentiment score and (B) most important trigrams in student feedback essays about growing strawberry plants at home in an online course at the University of Florida, Gainesville, during the Spring 2020 and Summer 2020 semesters. Sentiments were extracted using three general-use lexica: Afinn (Nielsen, 2011), Bing (Hu and Liu, 2004), and NRC (Mohammad and Turney, 2013). Most essays reflected positive sentiments as indicated by sentiment scores $>0$. Essays were grouped according to their overall sentiment score. Most important trigrams were identified using the term frequency-inverse document frequency index (tf-idf). Apostrophes and capitalization were removed during the text import steps necessary for text mining.

problem-solving, and knowledge application were tested. This activity fits the description of the inquiry dimension of hands-on activities proposed by Lumpe and Oliver (1991). Moreover, student weekly updates included evidence of experience (e.g., "I transplanted," "I plan," "I searched"), reflection (e.g., "stalks on my plant are dying, and I attribute this to a lack of direct sunlight"), abstraction ("growing fruits can be more challenging than aloe"), and experimentation (e.g., "I am watering roughly every 5 days. However, as we move closer to spring, I expect that to shrink to every 3 days or so."), suggesting the activity also had all the elements of the experiential learning cycle proposed by Kolb (1984). Thus, while the strawberry-growing activity in FRC 1010 was designed with modest student learning outcomes in mind, student feedback suggests that remote hands-on activities could potentially be used to target higher order learning outcomes in online horticulture courses.

Our results suggest that remote laboratories can improve the student experience in fully online courses, including high enrollment ones. Students enjoyed growing strawberry plants at home, except when plant health was compromised by biotic or abiotic factors. In our experience across two semesters, effort and resources allocated to remote laboratories are comparable to face-to-face laboratories. The teaching materials, recommendations, and challenges included in this document can inform instructors who are creating or refining hands-on activities for their online horticulture courses.

\section{Literature cited}

Alvarez, K.S. 2021. Using virtual simulations in online laboratory instruction and active learning exercises as a response to instructional challenges during COVID19. J. Microbiol. Biol. Educ. 22(1):1-4, https://doi.org/10.1128/jmbe.v22il. 2503.

Craver, J.K. and K.A. Williams. 2014. Assessing student learning from an experiential module in a greenhouse management course using hydroponics and recirculating solution culture. Hort Technology 24:610617, https://doi.org/10.21273/HORT TECH.24.5.610.

De Brey, C., T.D. Snyder, A. Zhang, and A. Dillow. 2021. Digest of education statistics 2019. Natl. Ctr. Educ. Stat. (NCES), Inst. Educ. Sci., U.S. Dept. Educ., Washington, DC.

Fry, J., S. Keeley, M. Hong, and M. Xiang. 2021. Evaluation of turfgrass establishment knowledge gained from an undergraduate horticulture course. North Amer. Colleges Teachers Agr. (NACTA) J. 65:46-49.

$\mathrm{Hu}, \mathrm{M}$. and B. Liu. 2004. Mining and summarizing customer reviews. Proc. Tenth Assoc. Computer Machinery Int. Conf. Knowl. Discov. Data Mining. 168-177, https://doi.org/10.1145/1014052.1014 073.

Kolb, D.A. 1984. Experiential learning: Experience as the source of learning and development. Prentice Hall, Englewood Cliffs, NJ.

Lindsey, A.J. 2019. Undergraduate student perceptions following participation in applied agricultural labs. North Amer. Colleges Teachers Agr. (NACTA) J. 64:454-465.

Lumpe, A.T. and J.S. Oliver. 1991. Dimensions of hands-on science. Amer. Biol. Teach. 53:345-348, https://doi. org/10.2307/4449322.

Mohammad, S.M. and P.D. Turney. 2013. Crowdsourcing a word-emotion association lexicon. Comput. Intell. 29:436-465, https://doi.org/10.1111/j.1467-8640. 2012.00460.x.

Nielsen, F.Å. 2011. A new ANEW: Evaluation of a word list for sentiment analysis in microblogs. 4 Aug. 2021. <https:// arxiv.org/pdf/1103.2903.pdf>.

Nunez, G.H. 2020. Using text mining to gauge student sentiments about hands-on activities in a protected agriculture course. HortTechnology 30:129-134, https:// doi.org/10.21273/HORTTECH04527-19.

Nunez, G.H. 2019. Sentiment analysis. 4 Apr. 2021. <https://github.com/ ghnunez/nunezlabuf $>$.

Nunez, G.H., A.P. Kovaleski, B. Casamali, and R.L. Darnell. 2016. Can science and genetics literacy affect student perception of genetically modified organisms? AgBioForum 19:44-53. 
Nunez, G.H., A.P. Kovaleski, and R.L. Darnell. 2014. Formal education can affect students' perception of organic produce. HortTechnology 24:64-70, https://doi. org/10.21273/HORTTECH.24.1.64.

Silge, J. and D. Robinson. 2016. tidytext: Text mining and analysis using tidy data principles in R. J. Open Source Softw. 1:37, https://doi.org/10.21105/joss.00037.

St. Hilaire, R., T.W. Sammis, and J.G. Mexal. 2009. Integrating hoop house construction and operation into an undergraduate general education horticulture class. HortTechnology 19:445-451, https:// doi.org/10.21273/HORTSCI.19.2.445.
Uchanski, M.E., K. Grover, D. VanLeeuwen, and R. Goss. 2015. Integrating hoop house construction and environmental data interpretation into an undergraduate general education plant science course. HortTechnology 25:247-252, https:// doi.org/10.21273/HORTTECH.25. 2.247 .

Volery, T. and D. Lord. 2000. Critical success factors in online education. Int. J. Educ. Manag. 14:216-223, https://doi. org/10.1108/09513540010344731.

Wickham, H., R. Francxois, L.A. Henry, and K. Müller. 2018. dplyr: A grammar of data manipulation. R package version 0.7.
6. 4 Apr. 2021. <https://cran.r-project. org/web/packages/dplyr/index.html>.

Wickham, H. 2016. Programming with ggplot2. In: Ggplot2 (p. 241-253). Springer, New York, NY, https://doi.org/ 10.1007/978-3-319-24277-4_12.

Zimmerman, J. 2020. Coronavirus and the great online-learning experiment. 10 Mar. 2020. <https://www.chronicle. $\mathrm{com} /$ article/coronavirus-and-the-greatonline-learning-experiment $>$.

Zhou, R and D. Chen. 2021. Assessing students' perceptions of blended learning during the COVID-19 pandemic. North Amer. Colleges Teachers Agr. (NACTA) J. 65:50-56. 


\section{Transplanting a Strawberry Plant}

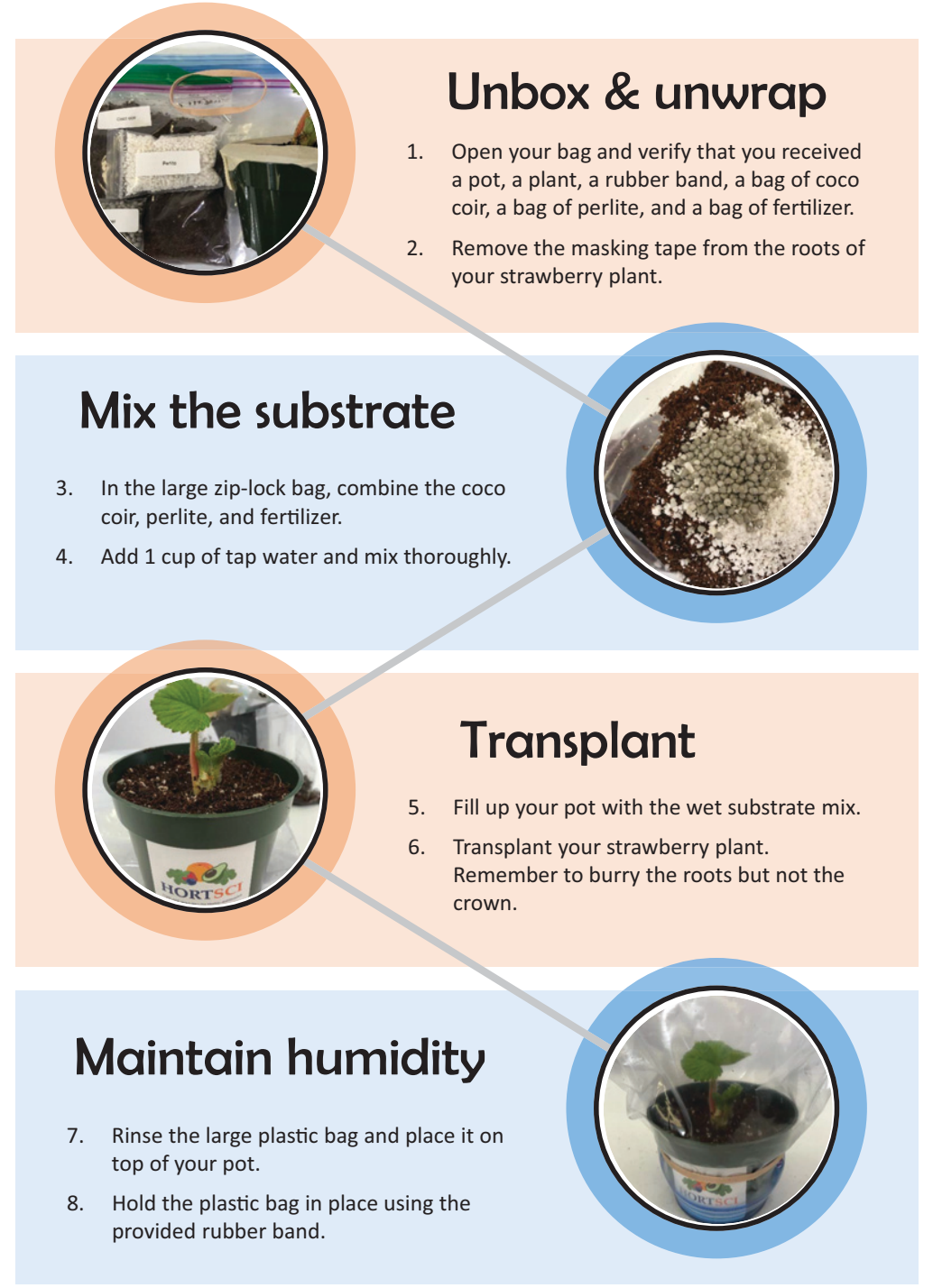

Supplemental Fig. 1. Infographics used to support instruction during a remote strawberry-growing exercise in an online undergraduate course at the University of Florida, Gainesville; 1 cup $=0.2366 \mathrm{~L}$. 


\section{Watering a Strawberry Plant}

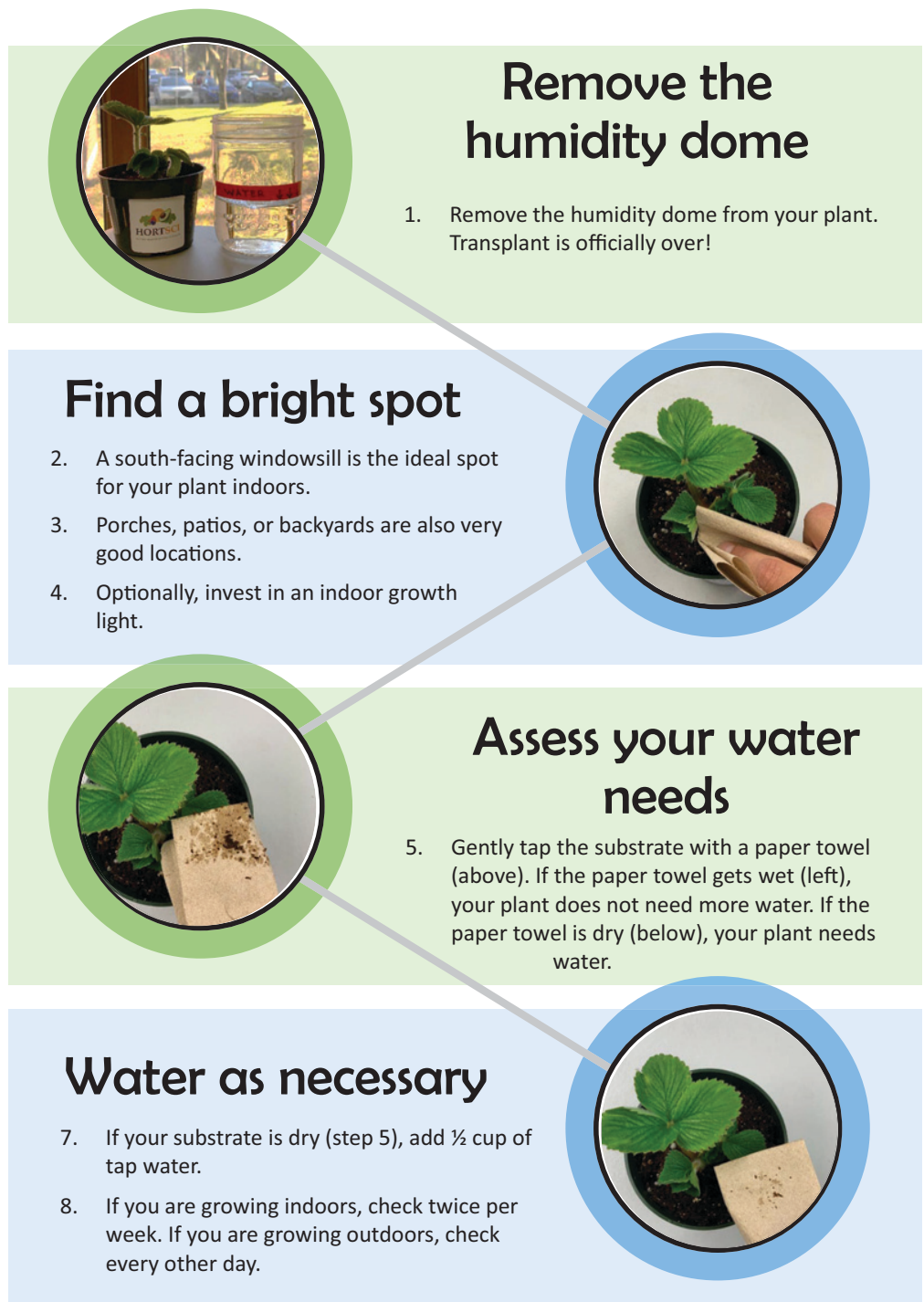




\section{Scouting for Pests \& Diseases}

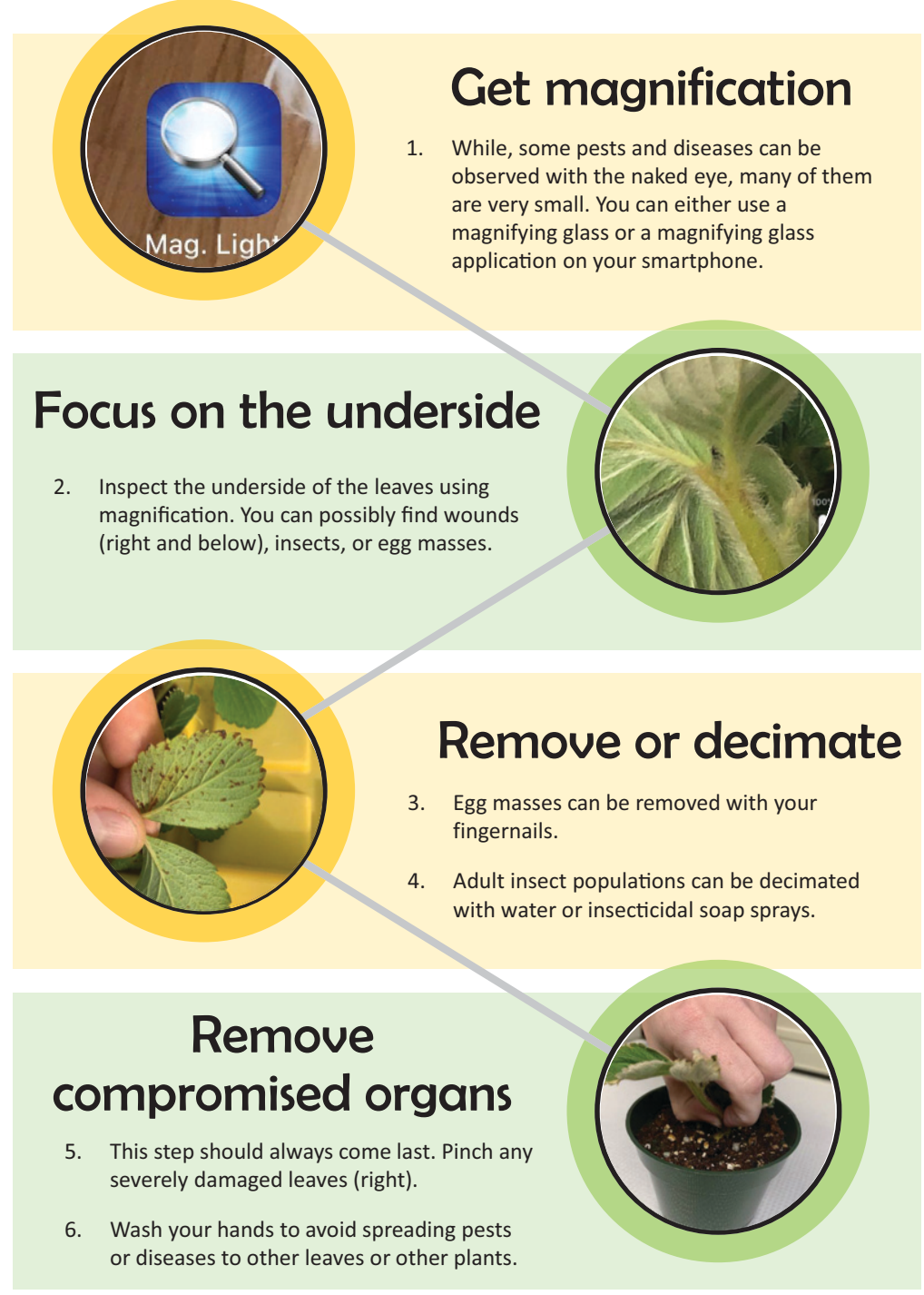




\section{Diagnosing Abiotic Stress}

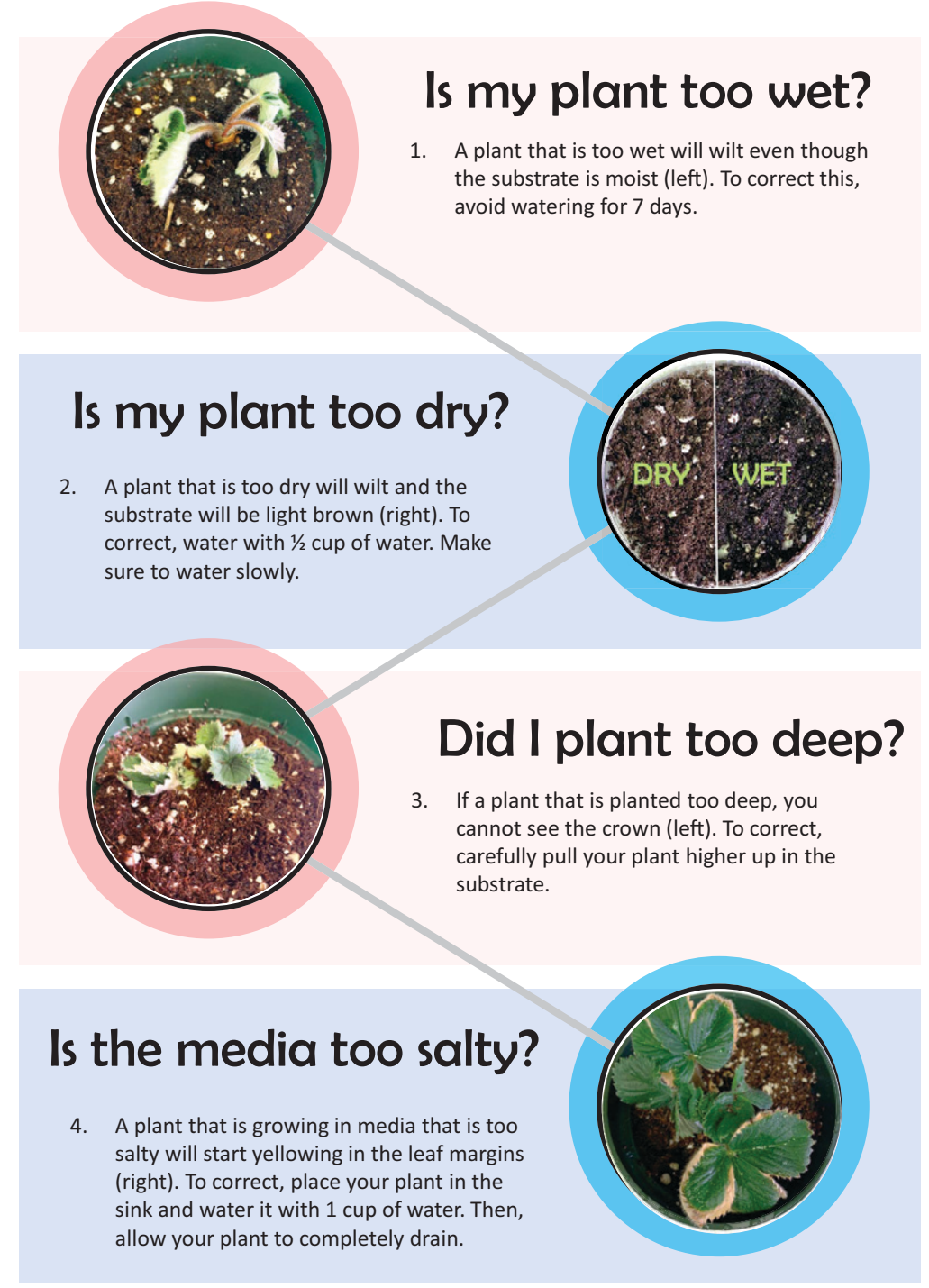




\section{Forecasting your harvest}

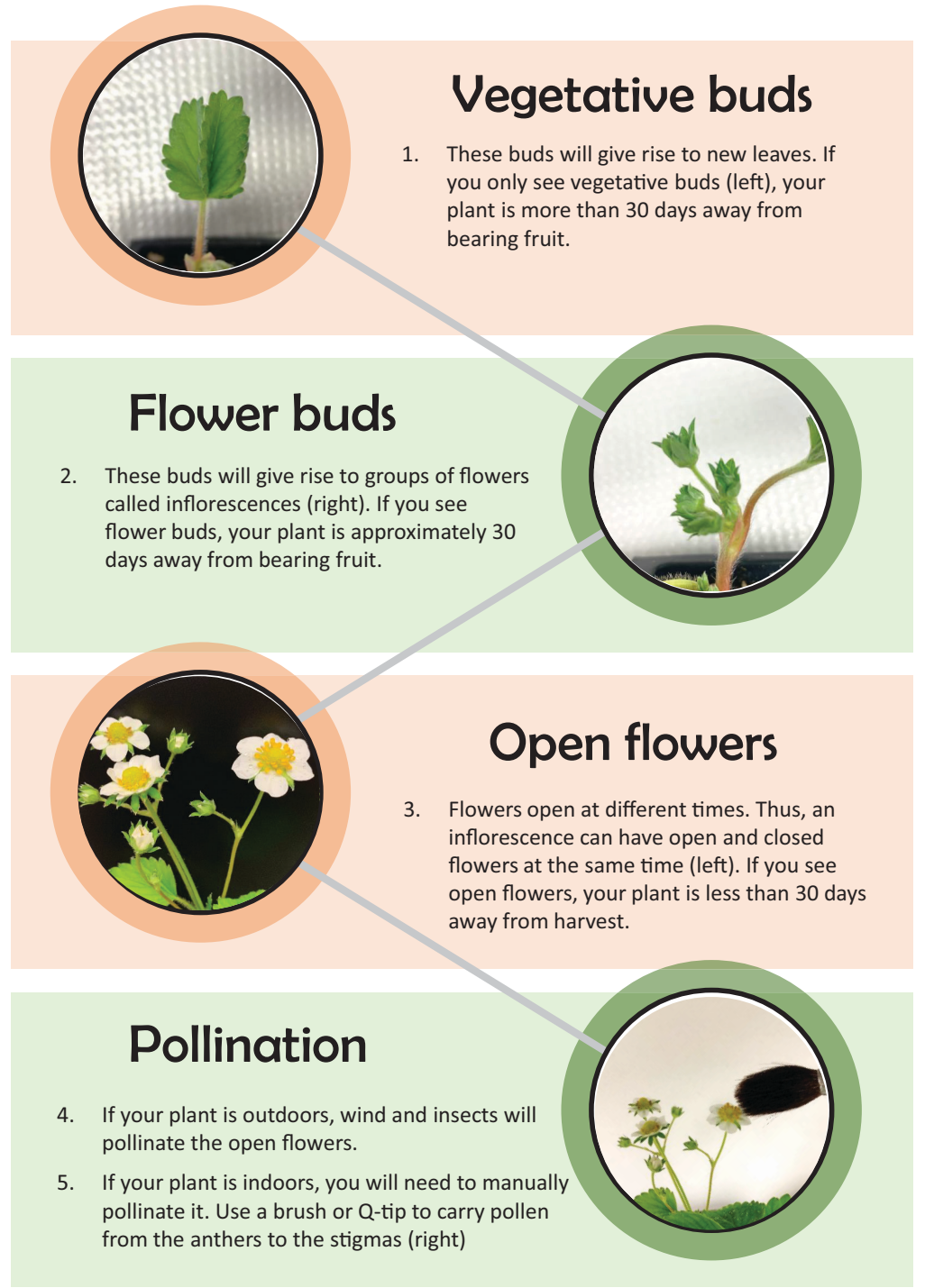

